\title{
BECOMING AN INTERPRETER: THE ROLE OF COMPUTER TECHNOLOGY
}

\author{
Annalisa Sandrelli \\ Annalisa.Sandrelli@unint.eu \\ Università degli Studi Internazionali di Roma (UNINT)
}

\begin{abstract}
In the mid-1990s, a few interpreter trainers began to realise that computer technology could be used to enhance classroom-based training and to support the students' autonomous learning. CAIT stands for Computer Assisted Interpreter Training and over the years this basic idea has developed in different ways, ranging from electronic resources to be used off-line by individual users to online speech repositories, and more recently to virtual learning environments where multiple users can interact as if in class. The paper provides an overview of key developments in CAIT and outlines existing paradigms and approaches.
\end{abstract}

\section{Riassunti}

A metà degli anni Novanta, alcuni docenti di interpretazione cominciarono a pensare che la tecnologia informatica potesse essere applicata alla didattica in aula e potesse fornire un valido aiuto ai discenti nelle attività di apprendimento autonomo. La sigla CAIT sta per Computer Assisted Interpreter Training (formazione di interpreti assistita dal computer); nel corso del tempo questa idea di base si è sviluppata in varie direzioni, dalle risorse elettroniche da usare offline individualmente a banche dati online di discorsi, fino ai più recenti ambienti di apprendimento virtuali nei quali più utenti possono interagire come se fossero in aula. Il presenta lavoro traccia una panoramica delle principali fasi di sviluppo del CAIT, con relativi paradigmi e approcci.

Keywords: Interpreter training. CAIT. Electronic resources. Blended learning. Distance learning. 
Parole chiave: Formazione di interpreti. CAIT. Risorse elettroniche. Apprendimento blended. Apprendimento a distanza.

Manuscript received on April 14, 2013 and accepted for publication on November 13, 2013. 


\section{Introduction}

Technology has always played an important role in professional interpreting. After all, although oral translation has existed since man began to communicate, conference interpreting did not become a profession as such until the twentieth century and then flourished after World War II thanks to the technological developments that made simultaneous interpreting in the booth possible. After that, conference interpreting remained essentially the same for several decades; however, over the last fifteen years the advent of computer technology has had a dramatic impact on how interpreters prepare for each assignment (e.g. by searching for relevant information on the Internet, which implies being able to sift through all the material and organize the information efficiently) and how they actually perform their job (i.e. from the emergence of new interpreting modes to the use of computers in the booth). In addition, the use of ICT has become very common in education, so it is hardly surprising that interpreter trainers should begin to experiment with computer technology themselves. The first pioneering experiences involving the use of computers in interpreter training date back to the mid-1990s. Fifteen years later, the time has come to take stock of the situation and see where Computer Assisted Interpreter Training (CAIT) stands today.

This paper aims to show how the development of CAIT has been influenced by both technological progress and trends in pedagogical theory. The starting point is a brief summary of the main principles of interpreting pedagogy, to explain where CAIT may fit (\$2); this is followed by a section that outlines the main technological developments of the last fifteen years and their impact on CAIT (\$3); then a comprehensive overview of the main paradigms in the short history of CAIT is presented, with a review of relevant literature and a description of key experiences in this field (\$4), followed by some conclusions (\$5).

\section{Teaching interpreting: how is it done?}

Becoming an interpreter is the aspiration of the many young trainees who register for interpreting degrees all over the world. The underlying assumption, of 
course, is that interpreting can be taught and is not a "natural" gift. Although there are still significant differences among curricula worldwide, there is a general consensus on how to train interpreters (see for example Sawyer 2004 and Sandrelli 2007). Among the most important common elements shared by interpreter training degree courses, it is worth highlighting the following:

1. students are expected to have a high level of proficiency in their working languages, usually ascertained by means of an entrance test;

2. trainers are active professional interpreters;

3. training activities try to reproduce real assignments as closely as possible;

4. students are trained in both consecutive and simultaneous interpreting;

5. self-learning activities (i.e. autonomous practice sessions) are an integral part of interpreter training, and the time spent on these activities normally exceeds the available contact hours.

Let us have a quick look at all of these points. The first principle is indisputable: trainees need to be highly proficient in their languages, because the time factor plays a key role in interpreting. If their source language comprehension skills are poor, they will find it hard to process the message; if their target language production skills are insufficient, the end product will be of low quality.

The second and third points are closely linked. Interpreting is a service aimed at enabling real-time communication in multilingual settings of various types. In this sense, it greatly helps to have trainers who are practising interpreters themselves and are thus capable of providing market-relevant training. Teacher demonstration is a popular tool and quite rightly so: the trainers' professional competence is one of the basic tenets of interpreting pedagogy. Furthermore, interpreting exercises must resemble real-life events as much as possible, in order to promote situated learning: "for learning to be authentic and productive, learning tasks need to be embedded in their larger, natural complex of human activity" (Kiraly 2000: 43). Since it is not always possible to allow trainees to practise in real communicative events (e.g. in dummy booths during a real multilingual conference), other methods involving simulations (mock conferences), authentic recordings and class practice with live speakers are normally used in interpreter training institutions. This makes it easier for trainees to develop the correct approach to interpreting, i.e. remembering that interpreters are supposed to communicate the message to the target audience and not translate it "mechanically".

As regards the need to train students in both consecutive and simultaneous interpreting, this is easily explained by the fact that both modes are in 
demand and are routinely included in the recruitment tests of leading international organisations. Moreover, advanced training in both is a good basis for future specialization (i.e. whispered interpreting, telephone interpreting, videoconference interpreting, etc.).

The heavy reliance on autonomous learning probably requires a slightly longer explanation. Interpreting is a complex task with language-independent constraints (time factor, limited working memory capacity and split attention) and language-specific constraints. Research has shown that there are two sets of strategies that interpreters use, the skill-based strategy and the knowledge-based strategy:

The skill-based strategy is governed by stored patterns of automatic responses representing those parts of interpreting performance that can be carried out as a routine (welcoming, greetings, different points on an agenda, all the stereotypical parts of a conference or meeting, but also normal or non-marked sentence structures and verbal collocations) and are governed by automatic strategies. The knowledge-based strategy comes into play in novel situations for which actions must be planned on-line, using conscious analytical processes and stored knowledge. (Riccardi 1998: 174)

Therefore, professional interpreting is partly based on (semi)automatic responses to certain translation problems, such as frequent language-pair-related difficulties and fixed expressions. Over the years, interpreters accumulate strategies to deal with the routine aspects of speeches, which frees up cognitive resources to tackle "new" information. It is imperative that students acquire strategies to deal with foreseeable difficulties:

In translation and interpreting novices still need to engage in tactical learning whereby they learn specific rules for solving specific problems [...]. This tactical knowledge then becomes increasingly well organized and the novice develops a set of strategies designed to optimally solve the problems he encounters. (Moser-Mercer et al 2000: 110)

Such automated responses can only be achieved through deliberate practice. Moser-Mercer (2000, in Motta 2006) estimates that 3000-5000 hours of deliberate practice are required in order to achieve professional levels of expertise in interpreting. ${ }^{1}$

Most teaching models break the interpreting process down into discreet interpreting-related skills (e.g. listening, memorizing, note-taking, speaking, etc.), and students are required to perform one task at a time before attempting

1. Even after graduation, it takes some time before new interpreters can be considered true professionals: for example, AIIC admits new members with a minimum of 150 days of work experience. 
to combine and coordinate all of them in interpreting exercises proper (see Iglesias Fernández 2006 for a review of teaching approaches). Although each interpreter training institution has its own curriculum, with objectives and expectations regarding students' progress, interpreting teachers know that each student has a different learning curve and expected progression is only a general guideline: some students may need more practice than others and each student has his/her own strong points and weaknesses. This means that interpreter training certainly requires an individual focus and the long hours of autonomous practice are part and parcel of it.

However, there is an inherent contradiction between the great weight of autonomous learning in interpreter training and the prevailing teacher-centered (transmissionist) approach traditionally adopted in most institutions. That is the reason why in recent years there has been a shift towards a learner-centered (socio-constructivist) approach to interpreter training (and translator training as well), partly favoured by the very development of appropriate computer tools that can support the students' learning process (see Kiraly 2000, Motta 2006, Tymczyńska 2009, Skaaden \& Wattne 2009, among others).

A student-centered approach is certainly more effective, especially if it is accompanied by explicit guidance in assessing performance: feedback sessions after an interpreting exercise are much more useful if self-assessment and peer assessment are added to teacher assessment (Sandrelli 2007) (see §4.1); moreover, the development of self-assessment skills is essential for continuous professional development as well. In other words, it is possible for trainers to promote learning by encouraging collaboration and by providing guidance and feedback in class: knowledge is not transmitted by teachers to learners, but constructed by learners engaged in a collaborative dialogue (Moser-Mercer et al. 2005). It is also important to help trainees organize their autonomous practice sessions, especially in the early stages when beginners cannot be expected to take control of their own learning without aid (i.e. selecting materials, using them, assessing performance, etc.).

To sum it up, interpreter training is labour-intensive, time-consuming and partly based on constant drilling; it requires an individual learner focus but at the same time it feeds off collaboration among peers, with the ideal trainer role as a facilitator; and it must expose trainees to authentic (or realistically simulated) working situations. In the mid-1990s these very characteristics led a few interpreter trainers to start experimenting with computer technology, in an attempt to improve and supplement traditional training methods. Before embarking on a historical overview of CAIT (see §4), it is worth explaining 
where the interest in technology came from and how it has evolved as technological developments have gradually offered potential new applications.

\section{Interpreter training and technological developments}

The first, obvious reason why some interpreter trainers began to look at how computer technology could benefit interpreter training was the need to support the autonomous learning component of degree courses. By the mid1990s personal computers had become common in academic environments, at least in western countries, and were being used for teaching and learning purposes in all disciplines. In particular, computer technology was being used in the related field of foreign language learning (Computer Assisted Language Learning, or CALL), which had already accumulated considerable experience (see Warschauer 1996, Warschauer \& Healey 1998). Therefore, the basic idea of Computer Assisted Interpreter Training (CAIT) was to use computer technology to enhance classroom teaching and to support students' autonomous learning. At the time the multimedia capability of standard PCs was still limited (not all computers had good video cards, for example), not many students could be expected to have a computer at home, and those who did have one had very slow Internet dial-up connections, if any. Therefore, initially CAIT projects aimed to address only the repetitive drilling part of the training, by providing students with multimedia materials which they could use off-line in their self-study hours, mostly in open-access rooms on campus (\$4.1).

Until the beginning of the $21^{\text {st }}$ century these experiences had a limited diffusion, but as time went by the situation gradually improved: connection speeds increased and the technical specifications of standard computers became much higher, making it possible to work with truly multimedia materials; moreover, laptops became more common, thus justifying the expectation that students would have a home computer that they could use to prepare for classes or to carry out their autonomous learning activities. A further step that contributed to a wider use of ICT in education (and in interpreter training in particular) was the development of computer-mediated communication (CMC) tools: asynchronous CMCs include e-mail, newsgroups, webbased conferencing systems, wikis and so on, which can be used for collaborative text-based work; synchronous CMCs allow real time communication (written and spoken): chat tools, VOIP (voice Internet protocol) programs such as Skype, and so on.

Of particular relevance was the development of course management systems (CMSs), also known as virtual learning environments (VLE), i.e. online environments that provide teachers with the necessary tools to deliver their 
courses entirely or partially on-line. A prime example is Moodle, an opensource CMS used in many universities to teach a wide range of subjects. When installed on a server, it makes it possible to host many different "courses", each of them featuring a course diary to post announcements, a central storage area where audio, video and textual resources can be uploaded, and templates for the creation of exercises and tests. Moodle is essentially an online repository of course materials; however, it is also possible to create various discussion threads in a learner forum, to ask students to upload their work and give each other feedback, and so on. In this sense, various opportunities for asynchronous collaborative learning can be created and communication among students and between students and teachers is possible outside the classroom. Although Moodle is a general CMS and some of its functions are not especially relevant to interpreter training, it was soon adopted by many interpreter training institutions, initially to support students and teachers in the delivery of traditional face-to-face courses and then to explore the idea of delivering interpreter training courses in a blended learning format: the Geneva Virtual Institute was the first dedicated VLE developed specifically for interpreter training. So, while early CAIT projects only envisaged users interacting with the materials but not amongst themselves, the development of CMC tools and VLEs made various forms of interaction among multiple users possible, although mostly in an asynchronous form (\$4.2). Initially, interpreter trainers experimented only with the teaching of interpreting-relevant subjects (e.g. ethics, interpreting theory, terminology, etc.) in a blended or even a distance learning format, with the teaching of interpreting core subjects (simultaneous and consecutive interpreting, sight translation, etc.) provided as a mixture of residential classes and autonomous learning (Ko 2006, Skaaden \& Wattne 2009).

However, in recent years there have been attempts to deliver actual interpreter training on-line. There are several reasons for this. The first one is technological: the invention and the spreading of broadband connections (ADSL, and, a few years later, fiber-optic lines) have resulted in connection speeds increasing steadily not only on university campuses but also in private homes. Technological progress has finally given the interpreter training community the tools to have online real-time interpreting. The second one is economic: interpreter training courses have always been expensive to run for universities, since traditionally they have always had a very low teacher-student ratio (for the reasons outlined in \$1); the economic problems that began in the early years of the $21^{\text {st }}$ century and are still deeply felt in many countries have had a negative impact on university budgets. This has resulted 
in oversubscribed courses with reduced contact hours for the most popular language combinations (Blasco Mayor 2005, Jiménez Ivars 2006) and the cancellation of financially unviable courses (i.e. in language combinations with not enough students; Gorm Hansen \& Shlesinger 2007). Thirdly, there is increasing demand for training in public service interpreting, a sector in which the required language combinations are influenced by migratory movements and involve languages of limited diffusion (Skaaden \& Wattne 2009, Sandrelli 2011a). This causes problems when it comes to organizing face-toface courses: finding qualified tutors can prove problematic; potential students are usually adult learners who may be working already and may prefer a part-time blended course or even a distance learning course over a full-time residential one; and geographical distance may play a role too (it is no coincidence that the first experiences of this kind have taken place in countries like Canada, South Africa, Australia, Norway and Sweden, where population density is low and most educational opportunities are concentrated around the main cities).

As was mentioned in $\S 2$, one of the key principles in interpreting pedagogy is situated learning: as regards CAIT, this means using technology to recreate the interpreter's working environment(s) as closely as possible. In the current stage of CAIT (\$4.3), this goal can be achieved thanks to videoconferencing technology and 3D learning environments. Videoconferencing makes it possible (although by no means easy) to organize virtual classes (mock conferences, for example) involving students in different locations. 3D learning environments, on the other hand, are related to the gaming industry: the idea is to create "immersive" simulations of environments in which students can "meet" to practise interpreting in a conference centre or court or other venue.

These developments have gone hand in hand with university students' growing expectation that universities provide flexible tailor-made learning opportunities that go beyond the physical limits of classrooms and do not impose any specific user platform: many students now prefer working with the "touch" interfaces of Android tablets, smartphones and iPads rather than computers, but there are conflicting proprietary restrictions imposed by manufacturers which make it technically difficult to ensure access to all. Therefore, software developers are also working towards the goal of cross-platform accessibility of teaching and learning materials (\$4.3.1).

Interestingly, one of the factors that is giving interpreter trainers the impulse to carry on doing research on these issues comes from the world of professional interpreting itself. Indeed, there have been significant changes as a result of technological progress in the conference interpreting market as 
well. The availability of broadband connections has made remote interpreting (RI) and videoconference interpreting (VCI) a reality, especially in legal, medical, educational and business settings (Mouzourakis 2006, Braun \& Taylor 2011, Luccarelli 2012). As available connections and technology gradually improve everywhere, such "virtual meetings" are likely to become more and more common, since they make it possible to save time and money. In addition, today professional interpreters use many tools that simply did not exist fifteen years ago, such as notebooks, tablets, smartphones, terminology management software, and so on. All these changes mean that interpreters must learn to use the relevant tools and develop the skills they need to work in these new environments. This is especially important for the new generations of interpreters. So, as well as the above-mentioned economic and logistical factors affecting the organization of degree courses, one of the reasons for current developments in CAIT is that interpreter trainers are trying to ensure that the new interpreting graduates are equipped with market-relevant technological skills.

After this brief overview of the general technological development of the last fifteen years, let us have a more in-depth look at key CAIT experiences in the next section.

\section{CAIT: a periodization}

As the previous section has shown, despite its relatively short history (about fifteen years), it is possible to identify different stages of development of CAIT, during which specific teaching paradigms were adopted on the basis of the technology available at the time (for a fuller overview of the history of CAIT, see Sandrelli \& de Manuel Jerez 2007; Berber Irabien 2010; Sandrelli 2011a, 2011b).

\subsection{The early period}

The first period in the history of CAIT consisted in a series of pioneering experiences that were aimed at providing trainees with materials for autonomous learning, either on DVD or via the university network. These materials were designed for single users, and collaborative learning could only take place if students shared the same computer in class or during self-study hours. The most immediate application of this idea was the digitization of the old tape libraries to transform them into digital speech banks: the main advantages were better preservation of the materials (analogue recordings on tape were much more vulnerable), easier storage and easier search. A key project of 
this kind is Marius, developed at the University of Granada as a database of authentic speeches in Spanish, English, French and German from EU and national sources (De Manuel Jerez 2003, 2006; Sandrelli \& De Manuel Jerez 2007). The database was created using standard desktop software (Microsoft Access). All the available information on the resources (speaker-related, speech-related, and teaching indications) was entered into the database and the audio or video resources were added to it as embedded objects. By applying a filter to the relevant field it was possible to search the collection by topic, speaker, intended use (for consecutive or simultaneous interpreting practice), level of difficulty, etc.; moreover, by clicking on the audio/video resource, the media player program installed on the computer was launched automatically. The most valuable contribution of this project is the extremely detailed classification of authentic materials and the research done on the students' perception of the suggested level of difficulty and intended use of the materials, which has yielded interesting suggestions in terms of material selection (De Manuel Jerez 2006).

A similar idea was developed within a different technological framework at the University of Trieste: IRIS was a dedicated database that ran on the university local area network (LAN). As well as classifying the available digital resources according to a number of fields, it featured an in-built recording device and an email client to enable students to send their recordings and their translations to the teacher or to their peers (Carabelli 1999, 2003; Gran et al. 2002). A few years later the same basic idea was taken up again and developed further by other researchers, thanks to the availability of webbased communication tools (\$4.2.1).

During the same period, other trainers adopted a different approach, inspired by similar developments in CALL: they focused on developing dedicated interpreter training courseware (teaching software) and authoring tools, i.e. programs that provide exercise templates and tools within a single environment, thus making it easy for teachers who are not especially tech-savvy to create exercises. Trainers only need to select the audio, video and textual resources they want to use and assemble them into a single exercise file. The research centre leading this approach was the University of Hull. ${ }^{2}$

Initially, some interpreting teachers developed an interpreter training package for liaison interpreting practice: Interpr-It (De Ferra \& Cervato 1995)

2. At the time the University was the lead site of the TELL (Technology Enhanced Language Learning) Consortium and host of EUROCALL, the European Association for Computer Assisted Language Learning. TELL produced several authoring tools for language teachers and language learning courseware. 
was a CD with 8 interviews (Italian - English), with a modular structure, i.e. each interview was a self-contained interpreting lesson made up of a number of successive screens, presenting different exercises to be completed in a pre-arranged order. The software was meant for single users in self-access, both in a timetabled class and in the Open Learning centre accessible outside class hours (Sandrelli 2001). The materials only included audio and text, with no video recordings. This was a deliberate choice on the part of the developers: as has already been stressed elsewhere (Sandrelli 2011a: 240), trainers contemplating the introduction of ICT tools in their teaching must carry out a needs analysis first (i.e. identifying the role that CAIT tools could play in their specific educational setting) and then a feasibility study (i.e. establishing realistic goals on the basis of the technology accessible to the target group of students, on campus and/or at home). The use of the software was found to have a beneficial effect in terms of reducing anxiety levels when interpreting (Cervato \& De Ferra 1995, Sandrelli 2001).

The Interpr-It CD also included a consecutive interpreting module with a similar modular structure (Merlini 1996, Gran et al. 2002). It featured an on-screen interpreter notepad for students to type their notes whilst listening: although this solution could be seen as a limitation (typing is much slower and artificial than writing on paper), it had a specific pedagogical aim, namely forcing beginners to analyse the text and select key ideas. It is interesting to note that today this idea can be put into practice much more efficiently, thanks to the availability of smart electronic pens. The latter make it possible to take notes on special micro-chipped paper as if on ordinary paper, but with an added bonus: if the digital pen is connected to a PC and projector, it is possible to show the whole class the notes as they are being taken (by the trainer or by a student) and comment on their structure and strategies. Moreover, some smart pens have an in-built microphone that records the original speech: after the exercise you just need "[...] to tap on a word on the page of the notebook to hear the part of the speech related to that same word or a phrase played directly from the pen" (Orlando 2010: 77). Afterwards, the digital notes and the recordings can be sent to the trainer or other students for feedback.

The next project carried out in this period was called Interpretations: it was focused on simultaneous interpreting, but instead of creating a CD or DVD with a limited number of resources like Interpr-It, the idea was developing an authoring tool (or empty shell) with all the necessary tools to allow trainers to create their own materials (Sandrelli 2002, 2003a, 2003b). By then (the turn of the last century), the use of video resources had become much more widespread and most standard PCs had good multimedia capability. 
Dual-track recordings were also possible, to allow direct comparison of the source language speech with the target language rendition. Therefore, the developers of Interpretations designed an environment with a teacher interface (with authoring functions) and a student interface (with access to user functions only). For the trainers, this meant being able to structure their materials into courses, modules and exercises. Tools included a video editor to select part of a video/audio clip (without having to physically edit it), a recording device, a text editor to annotate texts, provide links and create text-based exercises, and many other functionalities. Students had to log in with an individual username and password and had a range of exercises to choose from: simultaneous interpreting with or without text, sight translation (with a static text or a rolling text that forced them to keep up with the teacher-imposed pace) and other types of preparatory exercises. Any work produced during each session was saved in the student personal folder, so at the end of each exercise, students could listen to their own rendition, compare it with the transcript of the original (if available), monitor the prosodic aspects of their performance by looking at the voice pitch graph displayed in the pitch tracker device, study the teacher notes provided, and so on.

Since the testing of the prototype proved successful, it was decided to develop it into fully-fledged commercial software, Black Box (Melissi Ltd). To facilitate the creation of exercises even further, an Exercise Wizard was added to the program to guide teachers step-by-step. As well as the functions previously available in Interpretations, it is also possible to manipulate the sound stream in the multimedia resources, for example by adding background noise effects to simulate interpreting under difficult working conditions; students can slow down the speeches without distorting the speaker's pitch if they are having trouble keeping up, and they can insert "bookmarks" in the speech to replay those sentences they found difficult. The student interface is icon-based, with tools that resemble a portable stereo; recordings can be compressed for storage on USB pen-drives, and sent via email to the teacher and/or to other students, if the program is installed on a LAN or as part of the Melissi Classroom (Sandrelli 2003a, 2003b, 2007; Sandrelli \& De Manuel Jerez 2007). In other words, while Interpretations had originally been developed as a single-user program, Black Box is envisaged both as a self-study tool and a collaborative tool. A pilot course was run at the University of Bologna at Forlì in which trainee simultaneous interpreters worked with the program in special classes to acquire self-assessment skills (Sandrelli \& de Manuel Jerez 2007). Trainers wishing to introduce an ICT tool should always contemplate a few classes to teach explicitly how to use computer-based materials properly 
and how to assess one's performance, to prevent loss of motivation and promote faster and more efficient learning.

\subsection{The middle period}

As was mentioned in $\$ 3$, around the turn of the century technological developments made it possible to create software and websites designed for multiple users. More specifically, the two main approaches adopted in this period involved the creation of web-based courseware, on-line speech banks and the use of Course Management Systems (CMS) or Virtual Learning Environments (VLE).

\subsubsection{Web-based courseware and on-line repositories}

This step in the history of CAIT is the on-line evolution of the courseware, authoring tools and speech bank experiences of previous years. Training materials were produced and put online, sometimes as a result of individual efforts, in other cases as the final output of large international projects. Today there is a growing number of websites with interpreter training materials: some of them are freely available, while others are only accessible to specific target groups (e.g. the students of a specific university).

Several institutions and interpreting associations have their own channels on YouTube or publish training videos on their websites. For example, the DG Interpretation's channel offers videos in which SCIC interpreters lead training sessions or describe their work (see SCIC). AIB, a consortium of Barcelona-based interpreters, also offers advice to budding interpreters by means of practical videos and tutorials (see AIB). IMPLI - Improving Police and Legal Interpreting, an EU-funded project, has produced training videos in six languages, available on the website (see IMPLI). Interpreters' personal blogs are other good sources of teaching and learning materials: the most popular is probably Andrew Gillies' page, full of useful suggestions, reading tips and exercises (see ITR). In all of these examples, the resources are open and freely available to anyone who may be interested; however, they are static resources, and the only possible interaction with the authors or other users is through the posting of comments on the websites. However, since these videos are the product of practicing interpreters and experienced interpreter trainers, they can be useful in maintaining the sense of authenticity in training.

A much more structured approach involves the development of courseware that is then made available on dedicated websites, often as the final output of research projects. They are essentially the online version of the 
CAIT courseware described in $\$ 4.1$, i.e. closed and self-contained collections of teaching materials. The basic principle in resources of this kind is guided learning: users are encouraged to explore the materials autonomously, for example, by clicking on the many hyperlinks provided and thus "discovering" information for themselves; however, there is a learning path that students are supposed to follow and certain activities have to be carried out in a pre-arranged order. The materials are designed to support autonomous learning, although they can also be used in class, under the trainer's guidance. No online interaction among users is envisaged. Examples of this approach are the website of the UK's National Network for Interpreting, with an interactive Interpreting Skills Map with multimedia exercises (see NNI), and ORCIT (Online Resources for Conference Interpreter Training), a project developed by a group of universities in seven European countries, with theory classes and structured exercises aimed at beginners in consecutive and simultaneous interpreting (see ORCIT).

A parallel development taking place roughly at the same time is the on-line version of speech banks. At their most basic, online speech banks function as a central storage space from which students can download interpreting materials (to be used offline) or upload their recordings to obtain feedback on their performance. This solution is adopted when the interpreter training course is delivered face-to-face and the online materials are intended for home use. In contrast with the above-mentioned websites, on-line speech banks are usually open collections of resources, meaning that new materials are constantly added to them to keep them relevant and in line with training needs. However, most of them are not freely available, since they usually require a log-on via username and password, and conditions to obtain credentials vary depending on the nature of the speech bank. By far the largest project of this kind is SCIC's Speech Repository, promoted by the EU's DG Interpretation with the aim of offering interpreter training institutions reallife speeches in many languages (all those of interest to EU institutions). Most of the material is from EU sources, but there are also speeches from national organisations and "pedagogical" speeches (i.e. non authentic), expressly prepared for beginners. In common with previous speech bank projects (see §4.1), the SCIC Repository can be searched by speaker- and speech-related parameters: when an interesting resource is found, it is possible to work with it online or download it. Trainees are also welcome to download a dedicated media player ("iRec") to play the chosen resource and also to record their own rendition and upload it to the server. iRec also works as a podcasting software: every time the application is started, it automatically checks the 
site for new content and downloads it. The repository keeps expanding year after year (currently, it holds about 2,300 speeches). In order to meet the expectations of users and assess their satisfaction, SCIC recently carried out a survey (Leitaõ 2012). On the whole, interpreting students and teachers are satisfied and tend to use these resources mostly in class; however, teachers also try to encourage trainees to use them for their self-study activities too. By contrast, individual interpreters are less happy with the Repository and would like more advanced-level resources. The thorniest issue has turned out to be the level of difficulty of the resources, since the perceptions of professional interpreters and trainees are very different in this respect and it is hard to meet the expectations of different user groups. Work is continuing to expand the collection in all the featured languages.

A recent addition to the list of on-line repositories is SPEECHPOOL (Leeds University and NNI), which aims to provide interpreting students worldwide with pedagogical speeches (i.e. not original speeches delivered in actual conferences). The main novelty of the project is the fact that the speeches are written and video-recorded by students for other students (Llewellyn Smith 2013). In other words, the multilingual website is a collaborative project (along the lines of Wikipedia), with interpreting students recording speeches in their working languages so that other students can benefit. The speeches are classified on the project website on the basis of several parameters, so that users can search for the resource they want. However, the video clips are uploaded to YouTube, so they do not take up space on the project server. Accompanying Facebook and Twitter pages are provided as a meeting point for users to seek and share advice (see SPEECHPOOL). The speeches are not graded by teachers but by users themselves, who can vote on the perceived difficulty of the resource they have just used for practice.

All of these "new generation" speech banks are constantly being expanded and allow users to download, upload and exchange materials: they are certainly more interactive than the "static" collections of the past. The Geneva Virtual Institute as a whole and the virtual classes in particular represent a step in that direction, in that they promote and encourage online collaborative activities at a distance (see \$4.2.2 and §4.3.1).

\subsubsection{CMSs in interpreter training courses}

In the last five to ten years Moodle has been adopted by several institutions to support teaching and learning in face-to-face interpreting courses, because it is free and relatively easy to use (Fictumová 2004, Sandrelli \& de Manuel Jerez 2007, Tymczynska 2009, Ibrahim-González 2011, Sandrelli 2011b): 
trainers upload materials for class preparation, and after each lesson they upload the resources used in class and more resources for homework and revision. Ibrahim-González (2011) reports that students have indicated that the main advantage of using Moodle is its flexibility and accessibility at all times; moreover, they also feel that they can work at their own pace.

In other cases the use of a CMS (Moodle or a commercial one) has been combined with the use of a digital language lab: in order to create a stronger link between class work and home practice, a range of structured activities has been created involving both the digital language lab and the CMS. For example, Jiménez Ivars (2006) describes how the recordings of students' performances at home are uploaded to the CMS and then peer-assessed as part of the course requirements for all students: this also helps tackle the problem of monitoring the work of very high numbers of students in certain language combinations, since the trainer cannot possibly provide constant feedback to all of them. Gorm Hansen \& Shlesinger (2007), on the other hand, discusses a similar technological set-up to tackle the opposite problem, i.e. the reduction in contact hours affecting the languages of limited diffusion such as Danish. They found that this solution could cater for different learning styles and different progression rates and helped reduce interpreting-related stress in class: this, in turn, had a positive effect on motivation and exam results.

A more recent development has tried to integrate several aspects of previous projects into one single environment: the Computer Assisted Platform (CAP) described by Lim (2013) is a dedicated VLE for interpreter training that also includes some tools generally associated with interpreter training courseware, such as the Glossary window for easy reference whilst interpreting. However, there is no built-in recording device (such as you find, for example, in Black Box), so students have to open an external tool (e.g. Audacity) if they want to record their renditions. A survey on the use of CAP was carried out on 21 students and the majority of them expressed the opinion that the platform is more convenient than traditional methods used in self-study, because the resources are selected and structured. Once again, this is an innovative way of supporting students' autonomous learning in face-toface courses.

As regards delivering interpreter training courses in a blended format, the first to embrace the idea was the University of Geneva, which began to develop a fully-fledged dedicated VLE in 2004. Today the Virtual Institute is used to support not only the MA interpreting students in Geneva but also the students on the "training the trainers" courses all over the world. In blended learning courses the previously-mentioned asynchronous and synchronous CMCs 
allow trainers to provide tutoring and students to carry out on-line collaborative tasks. The design of the Virtual Institute was inspired by socio-constructivism and offers a mixture of face-to-face and on-line activities, structured and unstructured activities, and individual and collaborative tasks (MoserMercer et al. 2005, Class \& Moser-Mercer 2006, Moser-Mercer et al. 2006, Seeber 2006, Moser-Mercer 2006). It also features a number of custom-made tools: SIMON, the Student Tracker and EVITA (ETI Virtual Interpreter Training Archives). SIMON (Shared Interpreting Materials Online) is an electronic speech bank (see \$3.2.1), a clearing house of materials for interpreter trainers who can share resources and approaches that have worked particularly well in their classes or ask other trainers for suggestions (Seeber 2006). The Student Tracker is an on-line tool used by teachers to enter grades and comments on student performance: students can check their progression and teachers can exchange private notes on special situations. EVITA is an e-journal used by students to set themselves objectives for each practice session; afterwards, they assess their performance in writing. Tutors have access to what the students have written and they provide written feedback; other students also have the space to add their comments (Motta 2006). This tool is aimed at encouraging reflective learning, developing students' self-assessment skills, and helping them identify their individual weaknesses and strong points.

\subsection{Recent developments}

The availability of broadband connections and of videoconferencing technology is the main technological factor behind recent developments in CAIT (see \$2): they have led to the first attempts to deliver interpreter training courses as distance learning modules and in particular to the so-called "virtual classes". The other trend that can be identified is the influence of the gaming world, resulting in interpreter trainers exploring 3D virtual reality environments.

\subsubsection{Distance learning courses and videoconferencing}

One of the first experiments in delivering a distance interpreting program took place in Canada at Vancouver Community College. Initially it involved the use of CD-ROMs of teaching materials; then a dedicated web-based course was developed, and some of the training videos are still available on YouTube. Videoconferencing for consecutive interpreting practice was also used. However, in 2012 the course was cancelled rather suddenly. The University of the Witwatersrand in South Africa developed a course that used a combination 
of distance education for the delivery of interpreting-relevant subjects (topic preparation, ethics, etc.) and face-to-face classes for actual interpreting practice (Ko 2006). The program is still available today, but while the liaison and legal interpreting courses are only offered face-to-face with an e-learning component to support autonomous learning (via a dedicated CMS), the conference interpreting course is mostly taught as a distance course, with a few days of concentrated master classes in Johannesburg at the end (see WITS). Similarly, Skaaden \& Wattne (2009) describe their experience of delivering a public service interpreting course in Norway via an e-learning platform and a limited number of weekends for face-to-face classes. The key challenges here are that learners are scattered throughout the country and the distance course is aimed at a multi-language group. In order to maintain motivation in this setting, learners need structure: "For the cyber-class to succeed, structure predictability and pace in the organization of the learning activities is a necessity. The student needs to know what to do, where and when" (Skaaden \& Wattne 2009: 78). Therefore, students are provided with a detailed week by week plan, with clear goals and work requirements. The asynchronous forum is used to illustrate case studies and promote reflection, while the chat tool is used to have real-time class discussions in a mixed language room or in separate language groups. The chat sessions are always focused on clear topics and practical tasks (e.g. contributing to the term bank) and they are moderated by a teacher. This set-up appeals to adult learners who are already practising interpreters and learn from each other by sharing their experiences. Once again, however, for actual interpreting practice, the face-to-face classes are exploited to the full during the residential weekends, i.e. real-time interpreting interaction does not take place online.

Actual online interpreting classes are routinely organized by the EMCI universities, in collaboration with SCIC: indeed, they are basically the electronic version of the pedagogical assistance that SCIC has always provided to interpreter training institutions (Durand 2012). There are bilateral virtual classes (involving SCIC and one university) and multilateral ones (with SCIC and two, three, or more universities). Both types involve the organisation of a live multilingual mock conference via videoconferencing technology, with trainees interpreting consecutively or simultaneously in their respective universities and SCIC interpreters giving them feedback. Despite the organisational and technical challenges, there are both budget-related and pedagogical benefits. Trainees benefit from the feedback provided by objective outsiders, in a situation that resembles contact with real clients; moreover, these "virtual classes" are a good opportunity to interpret live speakers of any language, 
including languages of limited diffusion; finally, they are also good opportunities for students to adapt to new working conditions. The University of Geneva, involved from the start in the development of virtual classes, makes all the mock conference broadcasts available on a website (see LIVE FTI).

Provided the necessary technology and support are there and a similar organisational set-up can be arranged, there is no reason why virtual classes of this kind should not be organised for the training of business, health or legal interpreters (Sandrelli 2011b). The main difficulty is that there is no such consortium of universities offering a joint MA in dialogue interpreting (or similar), so the logistics can be quite daunting. However, it is worth exploring these opportunities because there is a growing number of interpreting assignments in these sectors involving the use of videoconferencing technology: its use in teaching would help students become familiar with the challenges of interpreting via videoconferencing (see \$2). Moreover, virtual classes appear to be the only possible solution to the key problem in teaching dialogue interpreting with computer technology, that is, the lack of real human interaction: "Recorded dialogue can be used, but no real interaction with the materials is possible: if trainees mistranslate one segment of dialogue, the following turn does not change, because the student is not talking to a human being" (Sandrelli 2011b: 216). One of the pioneering projects in CAIT, Interpr-It (see \$3.1), had come up against this difficulty and decided to address only the transfer skills involved in dialogue interpreting, and not the dialogue management skills (e.g. turn-taking, dealing with the overlapping of different speakers, etc.). Albeit this new way of teaching is still in its infancy, there is definitely some interest in these possibilities, as testified by the research that is being produced on these topics (see for example Ko \& Chen 2011, D'Hayer 2012).

\subsubsection{D Virtual reality environments}

To my knowledge, the first mention of a virtual conference centre dates back to 2007, when Sandrelli \& de Manuel Jerez (2007: 295) hinted at the development of an interpreting booth simulator and virtual conference centre. In 2011 Melissi Ltd launched its Interpreting Suite Emulator, a multi-channel emulation of a conference interpreting system (see MELISSI). It is much cheaper than a professional conference interpreting system, since it is entirely digital (no cabling of any kind), and it has been developed specifically for training purposes, as shown by a number of features: for example, interpreting sessions are automatically recorded and stored on the PCs, and trainers can tune in to any student channel and send written feedback via a text message 
function. The Interpreting Suite Emulator has been devised for face-to-face classes, but provided Internet connections are fast enough and two interpreter training institutions use the tool, it could be used to organise virtual classes as well.

The IVY (Interpreting in Virtual Reality) project has taken up the idea of a virtual conference centre and decided to explore the applicability of 3D virtual reality environments to teaching. Project partners have chosen Second Life to develop teaching materials to train business interpreters and educate their clients. IVY features a number of environments (business rooms, court, lobby, etc.) and is populated by avatars (student representations) and robots (speakers "animating" recorded materials). There are different types of learning activities available: recorded monologues (for consecutive interpreting) and bilingual dialogues, all based on spoken corpora, that is, on authentic materials; and opportunities for live interpreter-mediated role plays (Braun $\&$ Slater 2013). Thus, IVY provides opportunities for immersive, situated and experiential learning in a single environment. Moreover, IVY promotes digital literacy and familiarization with new work settings, since it provides practice scenarios for phone interpreting and videoconferencing. The actual pedagogical impact of the IVY materials is currently being assessed (Tymczynska \& Kajzer-Wietrzny 2013, Braun et al. 2013) and the choice of Second Life does not mean that other approaches are not possible. However, it is interesting to see that the IVY project partners have decided to develop it even further in the EVIVA project and that similar ideas are also being explored elsewhere, independently of the IVY project (Sahin 2013). A virtual 3D world may be especially useful where training opportunities for certain language combinations are not available, or when there are no qualified trainers in a given area. However, it must be borne in mind that for the time being such solutions are not within easy reach for most interpreter training institutions, as they require very significant $R \& D$ efforts and constant technological support to students and trainers.

\section{Conclusions}

The present paper has tried to provide an overview of the main trends in the relatively short history of CAIT. As we have seen, in the first ten years or so CAIT was very much a niche trend, because most interpreter training institutions lacked the necessary technological infrastructure and not all interpreter trainers were (and are) tech-savvy. However, in the last five years there have been some very interesting developments. Interpreter training institutions have become more and more interested in blended learning, not least for 
economic reasons. There is growing interest in distance learning solutions as well, especially in community, legal and business interpreter training, sectors with challenges of their own. This renewed interest in CAIT stems from the belief that part of the solution may lie in the more widespread use of appropriate technology: it is a solution that makes a virtue of necessity, but also an attempt to make interpreter training more in line with market requirements, as we have seen. These developments aim to meet the expectations of today's students, as Gorm Hansen \& Shlesinger predicted seven years ago: "In the near future we expect students to be able to download materials to their cell phones, iPods, MP3 players or other hand-held devices, and practice interpreting whenever they have some time to spare" (Gorm Hansen \& Shlesinger 2007: 111).

Some of the developments described in this paper were utterly unthinkable fifteen years ago. However, it is important to remember that such advances have been made possible by technological progress but also (and more importantly) by the far-sightedness and creativity of interpreter trainers themselves. It will be interesting to see what will come next.

\section{References}

Berber Irabien, Diana. (2010) Information and Communications Technologies in Conference Interpreting. Tarragona: Universitat Rovira i Virgili. Unpublished $\mathrm{PhD}$ thesis. Electronic version available at: <http://www.tesisenred.net/bitstream/handle/10803/8775/tesi.pdf?sequence $=1>$

BLASCO MAYOR, María Jesús. (2005) "El reto de formar intérpretes en el siglo XXI." Translation Journal 9:1. Electronic version available at: <http://accurapid.com/ journal/3linterprete2.htm>

BRAUn, Sabine \& Judith L. Taylor (eds.) (2011) Videoconference and Remote Interpreting in Criminal Proceedings. University of Surrey. Electronic version available at: <http://www.videoconference-interpreting.net/BraunTaylor2011. html>

BRAUN, Sabine \& Catherine Slater. (2013) "Dialogue Interpreting in Virtual Reality: Creating Bilingual Dialogues for Interpreting Practice in a 3D Virtual Environment" InDialog Conference Mapping the Field of Community Interpreting Berlin 15-16 November 2013.

BraUn, Sabine; Catherine Slater \& Robert Gittins. (2013) "Evaluating the IVY 3D virtual environment with interpreting students and trainers." Unpublished paper presented at the International Conference Interpreter-mediated Interactions: Methodologies and Models. Rome: UNINT, 7-9 November 2013.

Carabelli, Angela. (1999) "Multimedia Technologies for the Use of Interpreters and Translators." The Interpreters' Newsletter 9, pp. 149-155. 
CARABELli, Angela. (2003) "A Brief Overview of IRIS - The Interpreter's Research Information System.” In: De Manuel Jerez, Jesús (ed.) (2003) Nuevas tecnologías y formación de intérpretes. Granada: Atrio, pp. 113-139.

Cervato, Emanuela \& Donatella de Ferra. (1995) "Interpr-It: A Computerised Self-Access Course for Beginners in Interpreting." Perspectives: Studies in Translatology 2, pp. 191-204.

Class, Barbara \& Barbara Moser-Mercer. (2006) "Designing Learning Activities for Interpreter Trainers: a Socio-Constructivist Approach to Training." In: Crawford, Caroline; Dee Willis; Roger Carlsen; Ian Gibson; Karen McFerrin; Jerry Price \& Roberta Weber (eds.) (2006) Proceedings of Society for Information Technology and Teacher Education International Conference 2006. Chesapeake, VA: AACE, pp. 295-300.

D’Hayer, Danielle. (2012) "Public Service Interpreting and Translation: Moving Towards a (Virtual) Community of Practice." Meta 57:1, pp. 235-247.

De MANuel JereZ, Jesús. (2003) "Nuevas tecnologías y selección de contenidos: la base de datos Marius." In: De Manuel Jerez, Jesús (ed.) (2003). Nuevas tecnologías y formación de intérpretes. Granada: Atrio, pp. 21-65.

De MANuel JeREZ, Jesús. (2006) La incorporación de la realidad profesional a la formación de intérpretes de conferencias mediante las nuevas tecnologías y la investigación en la acción, Unpublished PhD thesis. Universidad de Granada. Electronic version available at: <http://hera.ugr.es/tesisugr/15891574.pdf>

DuRAND, Claude. (2012) "Virtual Classes." Unpublished paper presented at the IVY (Interpreting in Virtual Reality) Research Seminar Exploiting Emerging Technologies to Prepare Interpreters and their Clients for Professional Practice. London, 23 November 2012.

FictumovÁ, Jarmila. (2004) "E-learning for Translators and Interpreters - The Case of LMS Moodle". The Consortium for Training Translation Teachers Project Paper. Electronic version available at: <http://isg.urv.es/cttt/cttt/ research/ fictumova.PDF>

GORM HANSEN, Inge \&Miriam Shlesinger. (2007) "The Silver Lining. Technology and Self-Study in the Interpreting Classroom." Interpreting 9:1, pp. 95-118.

GRAN, Laura; Angela Carabelli \& Raffaela Merlini. (2002) "Computer-Assisted Interpreter Training.” In: Garzone, Giuliana \& Maurizio Viezzi (eds.) (2002) Interpreting in the 21st Century. Challenges and Opportunities. Amsterdam/ Philadelphia: John Benjamins, pp. 277-294.

GRAN, Laura. (1998) "In-Training Development of Interpreting Strategies and Creativity." In: Beylard-Ozeroff, Ann; Jana Králová \& Barbara MoserMercer (eds.) 1998. Translators' Strategies and Creativity. Amsterdam: John Benjamins, pp. 145-162.

IBRAHIM-GONZÁLEZ, Noraini. (2011) "E-learning in Interpreting didactics: Students' attitudes and learning patterns, and instructor's challenges." 
JoSTrans. The Journal of Specialised Translation 16. Electronic version available at: <http://www.jostrans.org/issue16/art_gonzalez.pdf>

IGLESIAS FERNÁNDEZ, Emilia. (2006) La didáctica de la interpretación de conferencias. Teoría y práctica. Granada: Editorial Comares.

JimÉnEz IVARS, María Amparo. (2006) "Interconectividad en el marco de la formación virtual del intérprete". Paper presented at the Accessible Technologies in Translation and Interpreting Conference, University of Vic, 30-31 March 2006.

KirAly, Don. (2000) A Social Constructivist Approach to Translator Education. Manchester: St. Jerome Publishing.

Ko, Leong. (2006) "Teaching Interpreting by Distance Mode. Possibilities and Constraints." Interpreting 8:1, pp. 67-96.

Ko, Leong; Nian-Shing Chen (2011) "Online-interpreting in Synchronous Cyber Classrooms." Babel 57:2, pp. 123-43.

LEITAÕ, Fernando. (2012) "The Speech Repository." Unpublished paper presented at the IVY (Interpreting in Virtual Reality) Research Seminar Exploiting Emerging Technologies to Prepare Interpreters and their Clients for Professional Practice. London, 23 November 2012.

Lim, Lily. (2013) "Examining Students' Perceptions of Computer-Assisted Interpreter Training." The Interpreter and Translator Trainer (ITT) 7:1, pp. 71-89.

LLEWELLYN SMith, Sophie. (2013) "Speechpool." Unpublished paper presented at the 17th Conference DG Interpretation-Universities New modes of learning. Electronic version available at: <http://ec.europa.eu/dgs/scic/cooperation-with-universities/universities-conferences/17th/docs/10.s.llewellyn_ smith_speechpool.pdf>

LuCCARELl, Luigi. (2012) "Conference and Remote Interpreting: a New Turning Point?" Communicate! Electronic version available at: <http://aiic.net/ page/3590/conference-and-remote-interpreting-a-new-turning-point/lang/l>

MerLINI, Raffaela. (1996) "Interprit - Consecutive Interpretation Module." The Interpreters' Newsletter 7, pp. 31-41.

Moser-Mercer, Barbara; Barbara Class \& Kilian S. Seeber. (2005) "Leveraging Virtual Learning Environments for Training Interpreter Trainers." Meta 50: 2. Proceedings of the 50th Anniversary Conference of META, Montréal, April 7-9, 2005.

Moser-Mercer, Barbara; Barbara Class \& Kilian S. Seeber. (2006) "Community Building: Training Interpreter Trainers." In: Chai Mingjiong \& Ailing Zhang (eds.) 2006. Professionalization in Interpreting: International Experience and Developments in China. Shanghai: Shanghai Foreign Language Education Press, pp. 192-210. 
Moser-Mercer, Barbara; Uli H. Frauenfelder; Beatriz Casado \& Alexander Künzli. (2000) "Searching to Define Expertise in Interpreting." In: Englund Dimitrova, Birgitta \& Kenneth Hyltenstam (eds.) 2000. Language Processing and Simultaneous Interpreting. Interdisciplinary Perspectives. Amsterdam/ Philadelphia: John Benjamins, pp. 107-131.

MotTA, Manuela. (2006) "A Blended Tutoring Program for Interpreter Training." In: Crawford, Caroline; Dee Willis; Roger Carlsen; Ian Gibson; Karen McFerrin; Jerry Price \& Roberta Weber (eds.) 2006. Proceedings of Society for Information Technology and Teacher Education International Conference 2006. Chesapeake, VA: AACE, pp. 476-481.

Mouzourakis, Panayotis. (2006) "Remote Interpreting. A Technical Perspective on Recent Experiments.” Interpreting 8:1, pp. 45-66.

Orlando, Marc. (2010) "Digital Pen Technology and Consecutive Interpreting: Another Dimension in Note-taking Training and Assessment." The Interpreters' Newsletter 15, pp. 71-86.

RiCCARDI, Alessandra. (1998) "Interpreting Strategies and Creativity." In: BeylardOzeroff, Ann; Jana Králová \& Barbara Moser-Mercer (eds.) 1998. Translators' Strategies and Creativity. Amsterdam/Philadelphia: John Benjamins, pp 171-179.

SAHIN, Mehmet. (2013) "Virtual Worlds in Interpreter Training." The Interpreter and Translator Trainer (ITT) 7:1. Manchester: St. Jerome, pp. 91-106.

SANDRELli, Annalisa. (2001) "Teaching Liaison Interpreting: Combining Tradition and Innovation." In: Mason, Ian (ed.) 2001. Triadic exchanges. Manchester: St Jerome Publishing, pp. 173-196.

SANDRELli, Annalisa. (2002) "Computers in the Training of Interpreters: Curriculum Design Issues.” In: Garzone, Giuliana; Maurizio Viezzi \& Peter Mead (eds.) 2002. Perspectives on interpreting. Bologna: CLUEB, pp. 189-204.

SANDRELli, Annalisa. (2003a) "Herramientas informáticas para la formación de intérpretes: Interpretations y The Black Box." In: De Manuel Jerez, Jesús (ed.) 2003. Nuevas tecnologías y formación de intérpretes. Granada: Atrio, pp. 67-112.

SANDRELli, Annalisa. (2003b) "New Technologies in Interpreter Training: CAIT." In: Gerzymisch-Arbogast, Heidrun; Eva Hajicová; Peter Sgall; Zuzana Jettmarová; Annely Rothkegel \& Dorothee Rothfuß-Bastian (eds.) 2003. Textologie und Translation. Tübingen: Gunter Narr Verlag, pp. 261-293.

SANDrElli, Annalisa. (2007) "Designing CAIT (Computer-Assisted Interpreter Training) Tools: BlackBox." In: Gerzymisch Arbogast, Heidrun \& Sandra Nauert (eds.) 2007. Challenges of Multidimensional Translation. Proceedings of the Marie Curie Euroconferences MuTra: Challenges of Multidimensional Translation, Saarbrücken 2-6 May 2005. Electronic version available at: <http://www.euroconferences.info/proceedings/2005_Proceedings/2005_proceedings.html> 
SANDRELLI, Annalisa. (2011a) "Computer Assisted Interpreter Training (CAIT) for Legal Interpreters and Translators (LITs).” In: Townsley, Brooke (ed.) 2011. Building Mutual Trust: a Framework Project for Implementing EU Common Standards in Legal Interpreting and Translation. Middlesex University, pp. 234268. Electronic version available at: <http://www.lr.mdx.ac.uk/mutual-trust/ mtdocs/BMT\%20Report.pdf>

SANDRELli, Annalisa. (2011b) "Training in Business interpreting and the Role of Technology." In: Medina Montero, José Francisco; Sarah Tripepi Winteringham (eds.) 2011. Interpretazione e mediazione. Un'opposizione inconciliabile? Roma: Aracne, pp. 209-233.

SANDRELLI, Annalisa \& Jesús Jerez De Manuel. (2007) "The Impact of Information and Communication technology (ICT) on Interpreter Training: State-ofthe-Art and Future Prospects." The Interpreter and Translator Trainer 1:2. Manchester: St. Jerome, pp. 269-303.

SAWYER, David B. (2004) Fundamental Aspects of Interpreter Education: Curriculum and Assessment. Amsterdam/New York: John Benjamins.

SEEBER, Kilian S. (2006) "SIMON: An Online Clearing House for Interpreter Training Materials." In: Crawford, Caroline; Dee Willis; Roger Carlsen; Ian Gibson; Karen McFerrin; Jerry Price \& Roberta Weber (eds.) 2006. Proceedings of Society for Information Technology and Teacher Education International Conference 2006. Chesapeake, VA: AACE, pp. 2403-2408.

SKAADEN, Hanne \& Maria Wattne. (2009) "Teaching Interpreting in Cyberspace: The Answer to All Our Prayers?" In: De Pedro Ricoy, Raquel; Isabelle Perez \& Christine Wilson (eds.) 2009. Interpreting and Translating in Public Service Settings: Policy, Practice, Pedagogy. Manchester: John Benjamins, pp. 74-88.

TYMCZYNSKA, Maria. (2009) "Integrating In-class and Online Learning Activities in a Healthcare Interpreting Course Using Moodle." JosTrans: The Journal of Specialised Translation 12. Electronic version available at: <http://www.jostrans.org/issue12/art_tymczynska.pdf>

TYMCZYNSKA, Maria \& Marta Kajzer-Wietrzny. (2013) "The pedagogical evaluation of SL IVY with students of interpreting at AMU". Unpublished paper presented at the International Conference Interpreter-mediated Interactions: Methodologies and Models. Rome: UNINT, 7-9 November 2013.

WARSCHAUER, Mark. (1996) "Computer-Assisted Language Learning: An Introduction.” In: Fotos, Sandra (ed.) (1996) Multimedia language teaching. Tokyo: Logos International, 3-20. Electronic version available at: <http:// www.ict4lt.org/en/warschauer.htm>

WARSCHAUER, Mark \& Debora Healey. (1998) "Computers and Language Learning: An Overview." Language Teaching 31, pp. 57-71. Electronic version available at: <http://www.gse.uci.edu/person/warschauer_m/overview.html> 


\section{Web references}

AIB on YouTube: <http://www.youtube.com/user/Lourdesaib>

EVIVA Evaluating the Education of Interpreters and their Clients through Virtual Learning Activities <http://www.virtual-interpreting.net/eviva-project/>

IMPLI Improving Police and Legal Interpreting: <http://www.isit-paris.fr/ -ImPLI-Project-.html>

ITR Interpreter Training Resources: <interpreters.free.fr>

IVY Interpreting in Virtual Reality: < http://www.virtual-interpreting.net/ivy/>

LIVE FTI: <http://live.fti.unige.ch/>

MELISSI <http://www.melissi.co.uk/software/interpreting.html>

NNINationalNetworkforInterpreting:<http://www.nationalnetworkforinterpreting.

ac.uk/index.php/interactive-resources/interpreting-skills-map >

ORCIT Online Resources for Conference Interpreter Training: <www. orcit.eu>

SCIC DG Interpretation's Channel: <http://www.youtube.com/user/ DGInterpretation>

SPEECHPOOL: <http://www.speechpool.net>

WITS Language School: <http://www.witslanguageschool.com/Courses/ TranslatingandInterpretingLanguages.aspx>

\section{BIONOTE / NOTA BIOGRAFICA}

ANNALISA SANDRELLI is Lecturer in English Language and Translation at UNINT, where she teaches Consecutive Interpreting (English into Italian), Respeaking and Theory of Film Language and Audiovisual Translation. She previously taught at the universities of Hull (U.K.), Trieste and Bologna at Forlì. Her research interests include corpus-based interpreting studies, CAIT (Computer Assisted Interpreter Training), audiovisual translation (subtitling, dubbing, respeaking and audio-description) and legal interpreting and translation. She has taken part in several national and European research projects, including "Building Mutual Trust" on the training of legal interpreters and translators (2008-2010) and "Qualitas" (2012-2014) on certification schemes for legal interpreters in Europe. She is currently involved in "Understanding Justice" (2014-2016) on interpreters in civil and commercial mediation, and in the "Eurolect Observatory" (2013-2015), on the special features of EU legal varieties of national languages. She is also one of the founding members of LARIM, a research group on interpreter-mediated interactions; and she coordinates the Rome unit of the DubTalk project, a corpus-based study of the language of films and TV series and their Italian dubbed target texts. 
ANNALISA SANDRELli è Professore Aggregato in Lingua Inglese e Traduzione presso la UNINT, dove insegna Interpretazione Consecutiva, Respeaking e Teoria del Linguaggio Cinematografico e della Traduzione Audiovisiva. In passato ha insegnato presso le università di Hull, Trieste e Bologna (Forlì). Tra i suoi interessi di ricerca ci sono gli studi sull'interpretazione con la metodologia dei corpora, il CAIT (Computer Assisted Interpreter Training), l'interpretazione in ambito giuridico e la traduzione audiovisiva (sottotitolazione, doppiaggio, respeaking e audiodescrizione). Ha partecipato a vari progetti nazionali e europei, tra cui "Building Mutual Trust" (2008-2010) project sulla formazione degli interpreti e i traduttori in ambito giuridico, e "Qualitas", relativo alla certificazione degli interpreti giudiziari in Europa. Attualmente partecipa a "Understanding Justice" (2014-2016), sugli interpreti nella mediazione civile e commerciale, all'Osservatorio sull'Euroletto (2013-2015), sui tratti distintivi delle speciali varietà comunitarie delle lingue nazionali. E' tra i fondatori del laboratorio LARIM sulle interazioni mediate da interpreti, e coordina l'unità di ricerca romana del progetto DubTalk, uno studio di corpus sulla lingua dei film e delle serie TV e relative versioni doppiate in italiano. 